\title{
Papers and RBEB - Some thoughts on the first days and the new challenges
}

\author{
Wagner Coelho de Albuquerque Pereira \\ SBEB - President \\ RBEB - Area editor
}

I have been connected to Biomedical Engineering since 1981 when I started my M.Sc. course. I had the privilege of witnessing the birth of our "beloved child" RBEB, at that time under the umbrella of the RBE (Revista Brasileira de Engenharia) as "Caderno de Engenharia Biomédica (RBE-CEB)". RBEB holds a special place in my career since it was in this journal that I published my first paper (vol.2. n.1, 1984). In those days, everything was "for real". I mean, the first version of a paper was really on paper sheets and called a manuscript because it really was a handwritten text. For those of you who were born after 1980, you have no idea how long it used to take just to let all the authors read and comment the text and then type the final version in a modern IBM typewriter (supposing you could read the handwriting of all authors). Every equation and symbol demanded a change in the typing globe of the typewriter and it had to be made manually. All we hopped for was that we could find the symbols we were looking for, otherwise there was no other way but change and rewrite parts of the manuscript. When the final version was ready, we had to post it to the journal - not via email, but rather via the post office. After some 4-6 months, we would receive the letter with the final decision. Opening that letter was not easy because in the most optimistic scenario it would take you like 3 months to answer the reviewers' questions, correct the manuscript, retype everything and send it back to the journal for the next round. Now everything is digital and the procedures changed drastically.

Our journal has been through all that and more. I recall the several times we discussed the future of RBEB in the General Assembly of our Society. Should it be simply extinguished or would we keep it in the "Intensive Care Unit" for another 2 years? Well, time has passed since those early days and we could see our child become a teenager with the efforts of many from the editorial board as well as from the SBEB's board of directors. Our teenager now is a young adult and has opened its horizons not only to its "mother region", but further!

Now our community is discussing a whole new set of issues. It is a pleasure to see that we are having a healthy debate among us that permeates new strategies to move the journal towards higher grounds, such as reaching the ISI and elevate our impact factor - the latest involving the choice of a possible new name for the journal, motivated by the transition to full English early this year. This is an irrefutable sign that nobody doubts that we should continue to boost RBEB and that it will prevail.

I would like to take this opportunity to congratulate the pioneers that have struggled to bring RBEB from birth to these days and invite new pioneers to join and help us to surpass the next challenges along the way.

Finally, I hope we can all meet next October in Uberlandia for the 24th edition of the Brazilian Congress on Biomedical Engineering. It shall be a great moment to get together, update with the new developments, share experiences and have pleasurable conversations with old and new friends. 
